\title{
Expression of NAC transcription factor is altered under intermittent drought stress and re-watered conditions in Hevea brasiliensis
}

\author{
Lisha P. Luke $\cdot$ M.B. Mohamed Sathik $\cdot$ Molly Thomas $\cdot$ Linu Kuruvilla $\cdot$ K.V. Sumesh
}

Received: 19 May 2017 / Revised: 15 June 2017 / Revised: 19 June 2017 / Accepted: 20 June 2017

(c) Korean Society for Plant Biotechnology

\begin{abstract}
Drought stress is one of the important factors that restrict the expansion of Hevea brasiliensis cultivation to nontraditional regions experiencing extreme weather conditions. Plants respond to drought stress by triggering expression of several drought responsive genes including transcription factors which in turn trigger expression of various downstream signalling pathways and adaptive networks. Expression of such drought responsive genes may revert back to their original level upon re-watering. However, no reports are available on such phenomenon in Hevea and hence, this study was initiated. For this purpose, NAC transcription factor ( $N A C$ $t f)$ was chosen as candidate gene. Its expression levels were monitored under intermittent drought as well as irrigated conditions in two clones (RRII 105 and RRIM 600) of $H$. brasiliensis with contrasting tolerance level. Copy number of $N A C$ tf was found similar in both the clones. Expression of $N A C t f$ was found highly up-regulated in RRIM 600 (a relatively drought tolerant clone) than in RRII 105 (a relatively drought susceptible clone) throughout the drought incidences which upon re-watering, reached back to its original levels in both the clones. The study indicated the existence of an association between expression of $N A C t f$ and drought tolerance trait exhibited by the tolerant clone RRIM 600. The study also proves the influence of drought and re-watering on the leaf photosynthesis and expression of $N A C t f$ in $H$. brasiliensis.
\end{abstract}

Keywords Hevea brasiliensis, intermittent drought stress and watering, NAC transcription factor, quantitative expression analysis

L. P. Luke $\cdot$ M. B. Mohamed Sathik $(\bowtie) \cdot M$. Thomas $\cdot$ L. Kuruvilla $\cdot$ K. V. Sumesh

Rubber Research Institute of India, Rubber Board, Kottayam 686009, India

e-mail: sathik@rubberboard.org.in

\author{
Abbreviations \\ tf: $\quad$ Transcription factor \\ RRII: Rubber Research Institute of India \\ A: $\quad \mathrm{CO}_{2}$ assimilation rate \\ gs: $\quad$ Stomatal conductance \\ qPCR: quantitative PCR \\ RQ: $\quad$ Relative quantification \\ Ct: threshold cycle
}

\section{Introduction}

Drought is one of the most devastating abiotic stresses, which negatively influences plant growth and development in general (Deikman et al. 2012) and it is the most important factor that restricts the expansion of Hevea brasiliensis cultivation to newer areas in several rubber growing countries (Sethuraj, 1986). Soil and atmospheric drought, high atmospheric temperature, high light and low relative humidity occurring at the same time severely affect the growth and yield of natural rubber (Chandrasekhar et al. 1990; Jacob et al. 1999; Devakumar et al. 1998). Different genotypes adopt different survival mechanisms to acclimatize to extreme climatic conditions.

Plants have evolved various survival strategies to overcome water deficit conditions and at the molecular level, several transcription factors are triggered which function as central regulators and molecular switches for gene expression in stress signaling and adaptation networks (Zhang et al. 2011). Transcription factors (Tfs) play important roles in plant stress responses by regulating various signalling pathways through their binding to the cis-acting elements located in promoter region of downstream target genes, thereby activating or repressing them. Many Tfs viz. WRKY (Rushton et al. 2012), zinc finger (Huang et al. 2009), AP2/ERF2 (Sakuma et al. 2002), MYB (Abe et al. 1997), ZmDREB2A 
(Qin et al. 2007) and NAC (Tran et al. 2004) have been characterized as drought-responsive.

NAC transcription factors comprise one of the largest gene families, which are only found in plants. NAM (no apical meristem), ATAF (Arabidopsis transcription activation factor), CUC (cup-shaped cotyledon) or NAC domain proteins possess a highly conserved N-terminal DNA binding domain (NAC) and a variable C-terminal transcription regulation region (TRR) which are known to activate or suppress transcription of many target genes (Ernst et al. 2004). The C-terminal regions of some $N A C t \mathrm{fs}$ also contain transmembrane motifs (TMs) which anchor to the plasma membrane (Tran et al. 2004; Nakashima et al. 2007). NAC genes have been reported to be involved in organ development and boundary maintenance, cell division, secondary wall synthesis, senescence, defence against pathogens and also act as master regulators in abiotic stress responses (Takada et al. 2001; Guo and Gan 2006; Kim et al. 2006; Uauy et al. 2006; Zhong et al. 2006; Puranik et al. 2012). In Hevea brasiliensis, along with expression of several drought responsive transcripts (Thomas et al. 2005; 2011; 2012; Sathik et al. 2011; Luke et al. 2015), differential expression of $N A C$ tf also was observed under drought stress. Further under drought stress, it was found significantly up-regulated in relatively drought tolerant Hevea clones while its expression was at minimal in the relatively susceptible clone (Thomas et al. 2011). Even though molecular effects of drought stress on plants are well documented, responses in plants to intermittent drought and re-watering are relatively unknown. The information generated on gene expression pattern under drought stress as well as associated with recovery from stress during re-hydration would provide a degree of cross verification of genes regulated by drought stress (Huang et al. 2008). To evaluate the level of expression of drought responsive transcripts in Hevea under drought and re-watered conditions, $N A C$ tf expression was taken as a candidate gene. Identification of drought responsive genes and validation of their association with drought tolerance are pre-requisites to establish if they can be employed in crop improvement programmes. Even though reports on gene response to drought stress and subsequent re-watering are available in other plants (Filippou et al. 2011), no such studies were reported in Hevea. Hence this study was conducted in Hevea with an aim to assess the molecular response to drought stress and re-watering with reference to a specific drought responsive gene viz $N A C t f$. Prior to validation of expression in different clones of Hevea with varying levels of drought tolerance, their copy number in clone RRII 105 and RRIM 600 was assessed. Expression of $N A C$ tf under drought and during re-watering was measured and the results are discussed.

\section{Materials and Methods}

Plant material and stress induction

Two Hevea clones, RRII 105 (relatively drought susceptible) and RRIM 600 (relatively drought tolerant) were chosen for the present study. The plants were produced by bud-grafting of seedlings with clonal buds collected from Hevea budwood nursery maintained at Rubber Research Institute of India (RRII) farm at Kottayam. The budded stumps were later transferred to polythene bags (size, $65 \times 35 \mathrm{~cm}$ ) and were grown in open field conditions at RRII as per the recommended package of practices (Mercykutty, 2008). After growing for six months (two to three whorl stage) in open field conditions, the plants were transferred to glass house for treatment. One group of plants was subjected to drought stress for five days and another group for ten days and both the groups were subsequently re-watered for another five days. This was followed by another similar cycle of drought stress and re-watering. The control plants were irrigated on alternate days to saturation level throughout the study period. Photosynthetic gas exchange parameters were recorded after each treatment ( 5 and 10 days after drought and five days after re-watering) during the three cycles. After each treatment, leaf samples were collected in liquid $\mathrm{N}_{2}$ for gene expression analysis.

Physiological parameters

The degree of impact of drought stress on young plants was assessed by measuring the net $\mathrm{CO}_{2}$ assimilation rate (A) and stomatal conductance $\left(\mathrm{g}_{\mathrm{s}}\right)$ using a portable photosynthesis system (LI-6400 XT), LI-COR, U.S.A. All the gas exchange measurements were made at a constant $\mathrm{CO}_{2}$ concentration of $400 \mathrm{ppm}$ using a $\mathrm{CO}_{2}$ injector (LI-6400-01, LI-COR, USA) and at $500 \mu \mathrm{mol} \mathrm{m} \mathrm{m}^{-2}$ of light intensity using red LED source (with $10 \%$ blue light) attached with the leaf chamber.

Gene expression analysis

Total RNA from the leaf samples was extracted using Spectrum Plant Total RNA Kit (Sigma-Aldrich) followed by cDNA synthesis ( $4 \mu \mathrm{g}$ of total RNA as starting material) using Superscript III reverse transcriptase (Invitrogen) following 
Table 1 Genes and the corresponding primers used for qPCR analysis. GAPDH gene was used as internal control and $H b C O I 1$ gene was used for comparison of expression

\begin{tabular}{cccc}
\hline Sl. No. & Gene & Forward primer $\left(5^{\prime}{ }^{\prime} 3^{\prime}\right)$ & Reverse primer $\left(5^{\prime}-3^{\prime}\right)$ \\
\hline 1 & $\begin{array}{c}\text { HbDRT5b } \\
\text { NAC } \text { tf })\end{array}$ & TCAAACACTGTCATGTCCAAGAAA & GAATCAGGGCAACCTTTTAAACC \\
\hline 2 & HbCOI1 & AGGTATTTGTGGGTGCAAGGTT & GGCGAGCCATTGCTAGAAGA \\
\hline 3 & GAPDH & GCCTGTGATAGTCTTCGGTGTTAG & GCAGCCTTATCCTTGTCAGTGAAC \\
\hline
\end{tabular}

the manufacturer's instructions. Quantitative PCR (qPCR) primers were designed (amplicon size $130 \mathrm{bp}$ ) using Primer Express software (Table 1) followed by synthesis (M/s. Ocimum Biosolutions, Hyderabad). Quantitative gene expression analysis was eventually carried out using Light Cycler 480 II, Roche Real Time PCR System. qPCR was performed in a $20 \mu \mathrm{l}$ reaction mixture containing $1 \mu \mathrm{l}$ from 1/10 dilution of first-strand cDNA reaction, $125 \mathrm{nM}$ of each primer and $10 \mu \mathrm{l}$ of Lightcycler 480 SYBR Green I Master (Roche Diagnostics Gmbh, Germany). qPCR was performed by incubation at $95^{\circ} \mathrm{C}$ for $7 \mathrm{~min}$, followed by 40 cycles of $95^{\circ} \mathrm{C}$ for 20 seconds and $60^{\circ} \mathrm{C}$ for 30 seconds. This was followed by a melt curve analysis $\left(95^{\circ} \mathrm{C}\right.$ for 20 seconds, $60^{\circ} \mathrm{C}$ for one minute and $95^{\circ} \mathrm{C}$ for 5 minutes). Each PCR with three biological replications was repeated twice or thrice in triplicates with null-template controls. Reaction efficiency of both the target genes and the endogenous control was calculated based on the formula, Efficiency $=10^{(-1 / \text { slope })}-1$. The primers were standardized based on serial dilution experiment and were ensured to have a slope value between -3.2 and -3.5 before proceeding for $\mathrm{qPCR}$ analysis. GAPDH was used as endogenous control. The relative quantification (RQ) values were analyzed (using Light Cycler 480 Software; release 1.5.0) and the expression rate is represented as fold change.

\section{Data Analysis}

The 2- $\triangle \triangle \mathrm{Ct}$ method was adopted to analyze the relative changes in gene expression from qPCR experiments (Livak and Schmittgen 2001). The data are presented as fold change in transcript level normalized to the endogenous control (GAPDH) gene, relative to that in irrigated plants. Statistical analysis was performed with the relative quantification data using ANOVA. The ratio with P-value $<0.05$ was adopted as significant for either down or up-regulation.

Plant material and stress induction for copy number determination of $N A C$ tf

Genomic DNA was isolated from leaf samples of RRII 105 and RRIM 600 as reported previously (Thomas et al. 2001). Optimum concentration of DNA and primers required for obtaining $\mathrm{Ct}$ value in the range of 20-25 was standardised. COIl, the coronatine insensitive gene (a single copy gene in Hevea) was used as reference (Peng et al. 2009) and GAPDH was used as internal control.

\section{Results}

Plants of both the clones (RRII 105 and RRIM 600) before imposing drought treatment had an $\mathrm{CO}_{2}$ assimilation rate (A) of about 10 and $11 \mu \mathrm{mol} \mathrm{m}^{-1} \mathrm{~s}^{-1}$, respectively (Fig. 1). Upon undergoing water deficit stress for five days, the A reduced to about $2.7 \mu \mathrm{mol} \mathrm{m}^{-1} \mathrm{~s}^{-1}$ in clone RRII 105 while RRIM 600 had $3.4 \mu \mathrm{mol} \mathrm{m}^{-1} \mathrm{~s}^{-1}$. Upon drought treatment for ten days, the A reduced further to about $0.8 \mu \mathrm{mol} \mathrm{m}^{-1}$ $\mathrm{s}^{-1}$ in clone RRII 105 while RRIM 600 had exhibited 1.6 $\mu \mathrm{mol} \mathrm{m} \mathrm{m}^{-1}$. Though A got reduced in both the clones, the clone RRIM 600 maintained better A than clone RRII 105. After ten days of withholding water, the plants were watered daily for five days. On the sixth day, A got improved to about $5.5 \mu \mathrm{mol} \mathrm{m}^{-1} \mathrm{~s}^{-1}$ in RRII 105 and $7.3 \mu \mathrm{mol} \mathrm{m}^{-1} \mathrm{~s}^{-1}$ in RRIM 600. When a second cycle of drought was imposed for five days on these plants, the A got reduced to

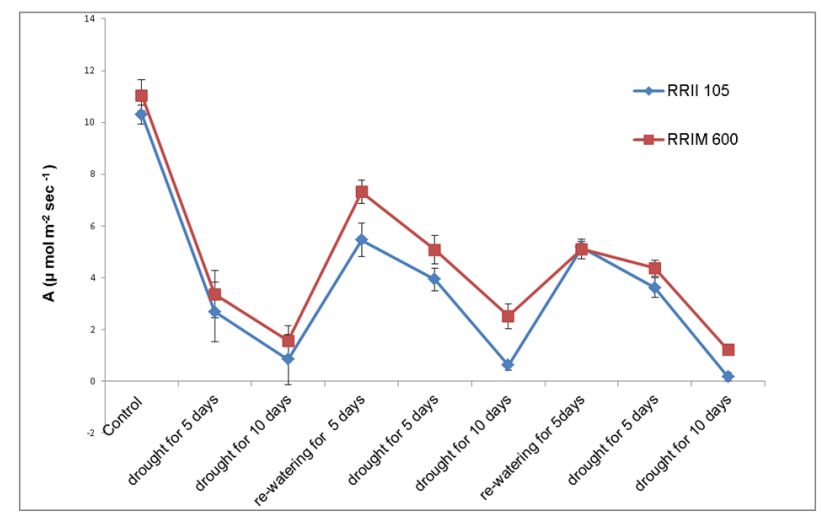

Fig. $1 \mathrm{CO}_{2}$ assimilation rate (A) measured in clones RRII 105 and RRIM 600 of Hevea brasiliensis under intermittent drought and watering cycles (during $5^{\text {th }}$ and 10 day upon each drought and re-watered periods) 
Table $2 \mathrm{Ct}$ values of NAC tf in RRII 105 and RRIM 600

\begin{tabular}{lcc}
\hline \multirow{2}{*}{ Gene } & \multicolumn{2}{c}{ Ct value } \\
\cline { 2 - 3 } & RRII 105 & RRIM 600 \\
\hline HbCOI1 & 21.53 & 21.18 \\
HbDRT5b $(N A C t f)$ & 21.69 & 21.74 \\
\hline
\end{tabular}

the levels of $3.3 \mu \mathrm{mol} \mathrm{m}^{-1} \mathrm{~s}^{-1}$ in RRII 105 and $5 \mu \mathrm{mol}$ $\mathrm{m}^{-1} \mathrm{~s}^{-1}$ in RRIM 600 respectively. When compared to the drought for 5 days on the first cycle, the reduction in A was lesser in the second cycle of drought. But when the drought was extended for ten days during the second cycle of drought, the A reduced to $0.6 \mu \mathrm{mol} \mathrm{m}^{-1} \mathrm{~s}^{-1}$ in RRII 105 and $2.5 \mu \mathrm{mol} \mathrm{m}^{-1} \mathrm{~s}^{-1}$ RRIM 600. This indicates that the reduction in A in susceptible clone was much more than the tolerant clone. When this was followed by another round of re-watering, A improved to about $5.1 \mu \mathrm{mol} \mathrm{m}$ $\mathrm{s}^{-1}$ in both the clones. When a third round of drought stress was imposed, the plants exhibited about 3.6 and $4.4 \mu \mathrm{mol}$ $\mathrm{m}^{-1} \mathrm{~s}^{-1}$ on the fifth day and about 0.17 and $1.2 \mu \mathrm{mol} \mathrm{m}^{-1} \mathrm{~s}^{-1}$ on the tenth day in RRII 105 and RRIM 600, respectively. Throughout the treatments (of intermittent watering and three rounds of drought treatment), clone RRIM 600 maintained better $\mathrm{A}$ indicating its drought tolerance nature. When A of clone RRII 105 during the third round of drought treatment reached near zero, RRIM 600 maintained A to the level of $1.2 \mu \mathrm{mol} \mathrm{m}^{-1} \mathrm{~s}^{-1}$. This indicates that RRIM 600 has the inherent capacity to perform well under drought stress by maintaining better $\mathrm{A}$.

In order to find if the copy number of $N A C$ if in the genome of the two clones was same, a PCR was performed using specific primers of $N A C$ if and a single copy gene COIl (coronatine insensitive gene 1) as reference gene (Peng et al. 2009). The $\mathrm{Ct}$ value of $N A C$ if in both the clones was found similar indicating that the copy number of this particular gene in both the clones did not differ (Table 2). Gene expression analysis of $N A C$ tf was performed in irrigated and drought treated leaf samples of the two clones (Fig. 2). After 5 days (during the first cycle of drought), its expression in clone RRIM 600 was about 5.5 fold higher while it was only 1.4 fold in RRII 105 than the respective watered controls. Interestingly, its expression got highly triggered to about 37 fold in RRIM 600 in drought treatment for 10 days while this was about only 2.7 fold in RRII 105 . During the subsequent watering treatment, the expression level was much lower (between 0.3 and 0.2 fold) in both the clones. While no much change could be observed 5 days of drought in both the clones, it got about 9 and 1.5 fold up-regulated in clones RRIM 600 and RRII 105 respectively in the second cycle of drought (10 days). Again

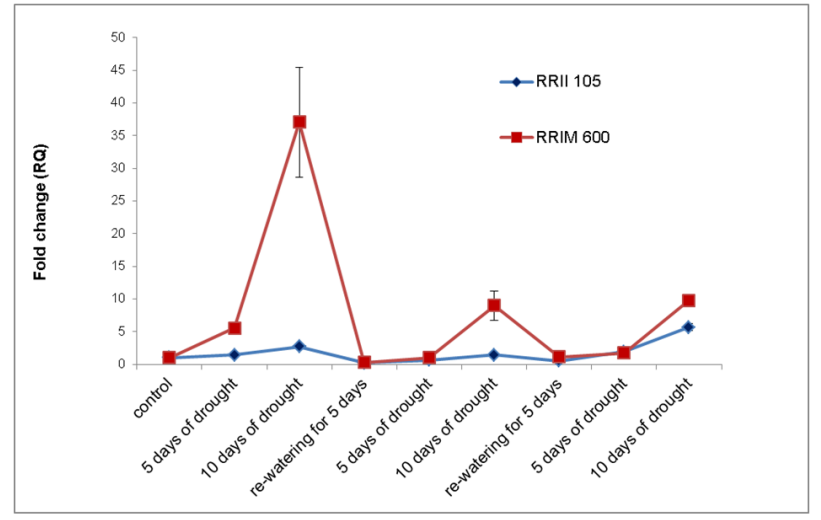

Fig. 2 Quantitative expression analysis of $N A C$ if in clones RRII 105 and RRIM 600 of Hevea brasiliensis under intermittent drought and watering cycles (during 5 and 10 days of drought treatment in each cycle). \pm Error bars indicate standard error of three biological replicates

during the second cycle of re-watering, while there was no much change in RRIM 600, it got 0.5 fold down regulated in clone RRII 105. During the third round of drought cycle, there was slight increase in both the clones (1.7 and 1.9 fold increase in RRIM 600 and RRI 105, respectively) on the $5^{\text {th }}$ day while there was about 9.8 and 5.7 fold increase in RRIM 600 and RRII 105 , respectively on the $10^{\text {th }}$ day. It was interesting to note that the levels of $N A C$ tf expression shot up to about 37 fold in clone RRIM 600 after 10 days of continuous drought treatment while it was only at meagre levels in clone RRII 105. Up-regulation of NAC tf only in the relatively drought tolerant clone (RRIM 600) during the subsequent drought cycles indicates its stronger association with drought tolerance. The up-regulation of $N A C$ If in RRII 105 in the third cycle of drought (5.7 fold increase) indicates that its up-regulation in this clone is much slower than that of RRIM 600 under repeated drought/watering cycles.

\section{Discussion}

During summer season in India, the agroclimatic regions like North Konkan, Maharashtra, Madhya Pradesh, Orissa which are prone to drought do not get summer showers. But the traditional regions often get intermittent summer showers which come as a boon thus saving crop plants from acute drought stress. Though it could be presumed that the summer shower helps the plants to recover from the severity of the drought, very few reports are available on its impact on the physiological and molecular aspects of rubber plants. Hence, this experiment was designed to study the effect of alternate cycles of drought and watering 
on photosynthesis $\left(\mathrm{CO}_{2}\right.$ assimilation rate) and expression of $N A C t f$. Our previous studies in Hevea also established $N A C$ if as stress responsive and to have much stronger association with stress tolerance (Thomas et al. 2011).

In the Indian rubber scenario, drought in both the traditional and non-traditional regions is severe during summer except for the fact that non-traditional regions are relatively warmer. The growth and productivity of Hevea plants are negatively influenced by drought (Sethuraj 1986, 1989; Chandrasekhar, 1990) while the photosynthetic mechanisms get severely affected under drought and high light thus leading to photoinhibition and photodamage (Devakumar et al. 2002, 1998; Jacob 1999). Irrigation during drought season resulted in better growth, leaf area index and photosynthesis (Vijayakumar et al. 1998, Devakumar et al., 1998, 1999). It is a common phenomenon that the leaves of Hevea under such prolonged water deficit conditions turn yellow and necrotic eventually leading to the death of the plants. Trees irrigated during drought season had resulted in better growth, leaf area index and photosynthesis (Vijayakumar et al. 1998, Devakumar et al. 1998, 1999).

Gas exchange parameters have been proven to be good indicators for evaluating the impact of stress on plants. But, the effect of long term drought with intermittent watering cycle on rubber had not been investigated earlier. In this study, both the clones maintained an optimum A at $10 \sim 11 \mu \mathrm{mol} \mathrm{m}^{-1} \mathrm{~s}^{-1}$ under optimum soil moisture conditions. Though A got reduced in the first days of drought treatment to near $3 \mu \mathrm{mol} \mathrm{m} \mathrm{m}^{-1} \mathrm{~s}^{-1}$ in both the clones, it went further down to less than 2 in RRIM 600 and below 1 in RRII 105. However, RRIM 600 maintained better tolerance than RRII 105 throughout the course of the treatment. Though A improved in both the clones during the subsequent irrigation cycles, it never regained its original level which indicates the severity of the damage inflicted upon the photosynthetic apparatus. Interestingly, the levels of $N A C$ if also showed the same trend.

Upon re-watering, many genes involved in growth, cell wall modification and lignin biosynthesis are up-regulated in addition to photosynthesis and re-hydration related genes (Zhou et al. 2007) while genes involved in stress protection mechanisms such as Early light inducible protein (ELIP) or LEA proteins and in detoxifying systems (thioredoxins) get repressed (Spiess et al. 2012). Transcription factors (tfs) for e.g. MYB, DREB, bZIP and WRKY have been found directly or indirectly involved in plant response to drought stress which generally get up-regulated under drought conditions and revert back to original levels under re-watered conditions (Golldack et al. 2014).
Prior to the selection of a candidate stress responsive gene, its copy number in genome should be ensured same in both the clones. Difference in copy number may end up with drastic change in their expression levels. For this purpose, a PCR was performed for $N A C$ if by using a single copy gene COII (coronatine insensitive gene) as reference gene (Peng et al. 2009). The results indicated that the copy number of $N A C$ if was same in both the clones (Table 2). Hence, $N A C$ if was employed further in the drought and intermittent re-watering experiment as reference gene. When the expression pattern of $N A C$ if under drought stress and subsequent re-watering was evaluated, $N A C$ tf was found up-regulated in the relatively tolerant clone RRIM 600 under drought stress and the expression was much higher after 10 days of drought imposition (37 fold) when compared to the irrigated plants whereas the level of expression was relatively lesser in RRII 105 . In the second and third cycle of drought also, NAC tf got highly up-regulated (8.9 and 9.7 fold) after 10 days of drought imposition in clone RRIM 600. Thus, the significant up-regulation in the levels of $N A C$ tf in RRIM 600 under drought stress might be associated with its inherent drought tolerance nature. Upon re-watering, the expression of $N A C$ if got repressed in both the clones followed by a gradual increase during the subsequent drought stress cycles. After second re-watering, the level of expression went back to levels similar to control in RRIM 600 and 0.5 fold in RRII 105 indicating the recovery to the normal levels.

Though both the clones exhibited a similar trend in expression of $N A C$ if under both drought stress and rewatered conditions, RRIM 600 exhibited relatively higher levels of expression thus conforming to our previous results as well as trend shown by physiological parameters in this study. From these results, it can be understood that the quantitative differences in the responses at the physiological and gene expression levels might have contributed to the increased drought tolerance observed in RRIM 600. The copy number of $N A C$ tf when estimated did confirm the fact that higher levels of $N A C$ if found in clone RRIM 600 was not due to any difference in the copy number of the same in both the clones but due to the inherent mechanism of up-regulation existing in clone RRIM 600. Another interesting feature is the higher levels of $N A C$ if to drought in the first cycle when compared to its level in the subsequent drought cycles. This indicates that the rate of response decreases gradually over the subsequent cycles of drought and re-watering. But among the clones studied, the tolerant ones always displayed better response to the drought/rewatering cycle. 
The physiological parameters indicated that drought stress leads to reduction in $\mathrm{CO}_{2}$ assimilation rate as well as poor crop performance while sub-sequent watering cycles help the plants to recover from stress though there were differences in its response among the clones studied. This study also confirmed the similarity in copy number of $N A C$ if in both the clones. The quantitative expression studies performed after confirming the similarity in copy number of $N A C$ if in both the clones revealed that expression of $N A C$ If is triggered as a response to drought in both the clones though at different levels. The level of $N A C t f$ in tolerant clone RRIM 600 was many folds higher than in the susceptible clone RRII 105. This study indicates the association between $N A C$ if and the drought tolerance trait. Above all, this study could establish influence of drought and subsequent re-watering cycles on photosynthesis and expression of $N A C \mathrm{tf}$. The study reiterates the relevance of $N A C \mathrm{tf}$ in drought response and in drought tolerance while opening up the possibility of employing this particular transcription factor in crop improvement programmes of Hevea brasiliensis.

\section{Acknowledgements}

The authors wish to thank Dr. K. Annamalainathan, Joint Director, RRII for his constant support and encouragement throughout the course of this work. Lisha is grateful to the Senior Research fellowship offered by RRII. Linu is grateful to Council of Scientific and Industrial Research, New Delhi for the Senior Research Fellowship.

\section{References}

Abe H, Yamaguchi-Shinozaki K, Urao T, Iwasaki T, Hosokawa D, Shinozaki K (1997) Role of Arabidopsis MYC and MYB homologs in drought- and abscisic acid-regulated gene expression. Plant Cell 9:1859-1868

Chandrasekhar TR, Jana MK, Thomas J, Vijayakumar KR, Sethuraj MR (1990) Seasonal changes in physiological characteristics and yield in newly opened trees of Hevea brasiliensis in North Konkan. Indian J Nat Rub Res 3:88-97

Chandrashekar TR, Marattukalam JG, Nazeer MA (1996) Growth reaction of Hevea brasiliensis to heat and drought under dry sub humid climatic conditions. Indian J Nat Rubber Res 9:1-5

Devakumar AS, Sathik MBM, Jacob J, Annamalainathan K, Prakash P, Vijayakumar KR (1998) Effects of atmospheric and soil drought on growth and development of Hevea brasiliensis. J Rub Res 1:190198

Devakumar AS, Sathik MBM, Sreelatha S, Thapliyal AP, Jacob J (2002) Photosynthesis in mature trees of Hevea brasiliensis experiencing drought and cold stresses concomitant with high light in the field. Indian J Nat Rub Res 15:1-13
Ernst HA, Olsen AN, Larsen S, LoLeggio L (2004) Structure of the conserved domain of ANAC, a member of the NAC family of transcription factors. EMBO Rep 5:297-303

Filippou P, Antoniou C, Fotopoulos V (2011) Effect of drought and rewatering on the cellular status and antioxidant response of Medicago truncatula plants. Plant Signal Behav 6:270-277

Golldack D, Li C, Mohan H, Probst N (2014) Tolerance to drought and salt stress in plants: Unraveling the signaling networks. Front Plant Sci 5: 151, doi:10.3389/fpls.2014.00151.

Guo Y, Gan S (2006) AtNAP, a NAC family transcription factor, has an important role in leaf senescence. The Plant Journal 46: 601-612

Hu R, Wu B, Zheng H, Hu D, Wang X, Duan H, Sun Y, Wang J, Zhang Y, Li Y(2015) Global reprogramming of transcription in Chinese Fir (Cunninghamia lanceolata) during progressive drought stress and after rewatering. Int J Mol Sci 16:15194-15219

Huang D, Wu W, Abrams SR, Cutler AJ (2008) The relationship of drought-related gene expression in Arabidopsis thaliana to hormonal and environmental factors. J Exp Bot 59:2991-3007

Huang XY, Chao DY, Gao JP, Zhu MZ, Shi M, Lin HX (2009) A previously unknown zinc finger protein, DST, regulates drought and salt tolerance in rice via stomatal aperture control. Genes Dev 23:1805-181

Jacob J, Annamalainathan K, Alam B, Sathik MBM, Thapliyal AP, Devakumar AS (1999) Physiological constraints for cultivation of Hevea brasiliensis in certain unfavorable agroclimatic regions of India. Indian J Nat Rub Res 12:1-16

Kim YS, Kim SG, Park JE, Park HY, Lim MH, Chua NH, Park CM (2006) A membrane-bound NAC transcription factor regulates cell division in Arabidopsis. The Plant Cell 18: 3132-3144

Livak KJ, Schmittgen TD (2001) Analysis of relative gene expression data using real-time quantitative PCR and the 2 ( - Delta Delta C (T)) method. Methods 25:402-408

Long SP, Humphries S, Falkowski PG (1994) Photoinhibition of photosynthesis in nature. Annu Rev Plant Physiol Plant Mol Biol 45:633-662

Luke LP, Sathik MBM, Thomas M, Kuruvilla L, Sumesh KV, Annamalainathan K (2015) Quantitative expression analysis of drought responsive genes in clones of Hevea with varying levels of drought tolerance. Physiol Mol Biol Plants 21:179-186

Mercykutty VC( 2008). Rubber Nursery oru prayogika guide. Rubber Research Institute of India, Kottayam

Nakashima K, Tran LS, Van Nguyen D, Fujita M, Maruyama K, Todaka D, Ito Y, Hayashi N, Shinozaki K, Yamaguchi- Shinozaki K(2007) Functional analysis of a NAC-type transcription factor OsNAC6 involved in abiotic and biotic stress responsive gene expression in rice. Plant J 51:617-630

Peng SQ, Xu J, Li HL, Tian WM (2009) Cloning and molecular characterization of HbCOI1 from Hevea brasiliensis. Biosci Biotechnol Biochem 73:665-670

Puranik S, Sahu PP, Srivastava PS, Prasad M (2012) NAC proteins: regulation and role in stress tolerance. Trend Plant Sci 17:369-381

Qin F, Kakimoto M, Sakuma Y, Maruyama K, Osakabe Y, Tran LS, Shinozaki K, Yamaguchi-Shinozaki K (2007) Regulation and functional analysis of $\mathrm{ZmDREB} 2 \mathrm{~A}$ in response to drought and heat stresses in Zea mays L. Plant J 50: 54-69

Rushton DL, Tripathi P, Rabara RC, Lin J, Ringler P, Boken AK, Langum TJ, Smidt L, Boomsma DD, Emme NJ, Chen X, Finer JJ, Shen QJ, Rushton PJ (2012) WRKY transcription factors: key 
components in abscisic acid signalling. Plant Biotechnol J 10:2-11

Sakuma Y, Liu Q, Dubouzet JG, Abe H, Shinozaki K, YamaguchiShinozaki K (2002) DNA-binding specificity of the ERF/AP2 domain of Arabidopsis DREBs, transcription factors involved in dehydration- and cold-inducible gene expression. Biochem Biophys Res Commun 290:998-1009

Sathik MBM, Luke LP, Thomas M, Sumesh KV, Satheesh PR (2011) Identification of drought tolerant genes by quantitative expression analysis in Hevea brasiliensis IRRDB International Rubber Conference, 15 -16 Dec. Chiang Main, Thailand

Sethuraj MR(1986) Physiology of growth and yield in Hevea brasiliensis. In "Proceedings of International Rubber Conference," 1986, Kuala Lumpur, Malaysia, pp. 3-19

Sethuraj MR, Potty SN, Vijayakumar KR, Krishnakumar AK, Rao PS, Thapliyal AP. Mohanakrishna T, Rao GG, Chaudhuri D, George MJ, Soman TA, Meenattoor JR (1989) Growth performance of Hevea in the non-traditional regions of India. In "Proceedings of the Rubber Research Institute of Malaysia, Rubber Growers' Conference, 1989," pp. 212-227. Malacca, Malaysia

Spiess N, Oufirb M, Matusikovac I, Stierschneider M, Kopecky D, Homolka A, Burg K, Fluch S, Hausman JF, Wilhelm E (2012) Ecophysiological and transcriptomic responses of oak (Quercus robur) to long-term drought exposure and rewatering. Environ Exp Bot 77:117-126

Takada S, Hibara K, Ishida T, Tasaka M (2001) The CUP-SHAPED COTYLEDON1 gene of Arabidopsis regulates shoot apical meristem formation. Development 128:1127-1135

Thomas M, Saha T, James J (2001) A note on the isolation and amplification of DNA from the bark tissues of mature trees of Hevea brasiliensis. Indian J Nat Rub Res 14:60-62

Thomas M, Saha T, Sathik MBM, Alam B, Ravindran M, Jacob J (2005) Differential expression of drought responsive transcripts in Hevea brasiliensis. Preprints of papers, International Natural Rubber
Conference, 6-8, November, 2005, Cochin, India, pp. 257-259

Thomas M, Sathik MBM, Saha T, Jacob J, Schaffner AR, Luke LP, Kuruvilla L, Annamalainathan K, Krishnakumar R(2011) Screening of drought responsive transcripts of Hevea brasiliensis and identification of candidate genes for drought tolerance. J Plant Biol 38\&39:111-118

Thomas M, Sathik MBM, Luke LP, Sumesh KV, Satheesh PR, Annamalainathan K, Jacob J (2012) Stress responsive transcripts and their association with drought tolerance in Hevea brasiliensis. J Plant Crop 40:180-187

Thomas M, Sathik MBM, Saha T, Jacob J, Schaffner AR, Luke LP, Kuruvilla L, Annamalainathan K, Krishnakumar R(2011b) Screening of drought responsive transcripts of Hevea brasiliensis and identification of candidate genes for drought tolerance. J Plant Biol 38\&39:111-118

Tran LSP, Nakashima K, Sakuma Y, Simpson SD, Fujita Y et al. (2004) Isolation and functional analysis of Arabidopsis stress inducible NAC transcription factors that bind to a drought responsive cis-element in early responsive to dehydration stress1 promoter. Plant Cell 16:2481-2498

Uauy C, Distelfeld A, Fahima T, Blechl A, Dubcovsky J (2006) A NAC gene regulating senescence improves grain protein, zinc, and iron content in wheat. Science 314:1298-1301

Zhang H, Jin J, Tang L, Zhao Y, Gu X, Gao G, Luo J (2011) Plant TFDB 2.0: update and improvement of the comprehensive plant transcription factor database. Nucleic Acids Res 39:1114-1117

Zhong R, Demura T, Ye ZH(2006) SND1, a NAC domain transcription factor, is a key regulator of secondary wall synthesis in fibers of Arabidopsis. The Plant Cell 18:3158-3170

Zhou J, Wang X, Jiao Y, Qin Y, Liu X, He K, Chen C, Ma L, Wang J, Xiong L, Zhang Q, Fan L, Deng XW (2007) Global genome expression analysis of rice in response to drought and high-salinity stresses in shoot, flag leaf, and panicle. Plant Mol Biol 63:591-608 